\title{
The consumers' emotional dog learns to persuade its rational tail: Toward a social intuitionist framework of ethical consumption
}

\author{
Lamberto Zollo - Accepted in Journal of Business Ethics \\ DOI: $10.1007 / \mathrm{s} 10551-019-04420-4$
}

\begin{abstract}
Literature on consumers' ethical decision making is rooted in a rationalist perspective that emphasizes the role of moral reasoning. However, the view of ethical consumption as a thorough rational and conscious process fails to capture important elements of human cognition, such as emotions and intuitions. Based on moral psychology and microsociology, this paper proposes a holistic and integrated framework showing how emotive and intuitive information processing may foster ethical consumption at individual and social levels. The model builds on social intuitionism to show how consumers' a priori affect-laden intuitive moral judgments impact their post hoc reflective moral reasoning. Symbolic interactionism is used to interpret consumers as interdependent and socially embedded agents that selfconstruct their social identity through interactions with other consumers. The proposed social intuitionist framework of consumers' ethical decision making shows that other-oriented moral emotions - such as elevation, gratitude, and empathy interact with persuasion and social influence in ethical consumption. Consequently, moral emotions and intuition drive interpersonal persuasion among ethical consumers. Theoretical propositions and implications for consumer ethics theory and practice are discussed.
\end{abstract}

Keywords: consumer ethical decision making; emotion; ethical consumption; intuition; persuasion; social influence. 
"I am not who you think I am;

I am not who I think I am;

I am who I think you think I am."

Charles Horton Cooley, Looking-glass self theory

\section{Introduction}

As consumers increasingly express concerns about environmental and social issues by choosing "green" and "fairly traded" goods (Harrison et al., 2005), business ethics and consumer behavior researchers are turning increasing attention to ethical consumption (Caruana et al., 2016; Chatzidakis et al., 2018). Ethical consumers support prosocial consumption and sustainability by avoiding products and services offered by companies that violate human rights, exploit labor, degrade environments, or trade unfairly (Shaw and Clarke, 1999). A poll of 30,000 consumers in 60 countries revealed that $66 \%$ of consumers, particularly young consumers, tend to choose products from sustainable brands (Nielsen, 2015). In fact, 73\% of Millennials - born from 1977 to 1995 - and $72 \%$ of respondents under 20 - Generation $Z$ - prefer brands that use pro-social advertising, sustainable manufacturing techniques, and ethical business standards (Forbes, 2017). However, the "30:3 phenomenon", also known as the ethical purchasing gap, shows that only one tenth of ethically concerned consumers actually purchase products and services from socially responsible companies (Shaw et al., 2016a). Consequently, contrary to attitudes and intentions, a gap occurs between their words and deeds (Carrington et al., 2016).

To investigate the discrepancies, the literature has usually adopted a rationalist and positivist perspective arguing that consumers make decisions according to conscious, intentional processes (Vitell et al., 2003). Building on rationalist cognitive models stressing moral reasoning (Rest, 1986), business ethics researchers have applied the general theory of marketing ethics (Hunt and Vitell, 1986) and contingency framework (Ferrell and Gresham, 1985) to theorize and investigate consumers' ethical decision 
making processes. Similarly, consumer behavior research has relied on the theory of planned behavior (TPB; Ajzen, 1991) to argue that consumers make deliberative and controlled ethical decisions (Shaw and Clarke, 1999; Vitell et al., 2013). However, social psychologists and management scholars are increasingly emphasizing nonrational elements to argue that emotions and intuition ${ }^{1}$ play significant roles in ethical decision making (Haidt, 2001; Sonenshein, 2007). Haidt's (2001) social intuitionist model is one of the most acknowledged perspectives in modern moral psychology (Evans, 2008; Kahneman, 2003). The model indicates that human cognition involves $a$ priori automatic and reflexive moral responses that impact post hoc deliberative and reflective moral reasoning. Haidt suggests that emotive and intuitive information processing systems (metaphorically the "emotional dog") are the main antecedents of moral judgment and reasoning (the "rational tail").

Business ethics scholars have applied the social intuitionist model to propose an integrated framework in which emotions and moral intuition are both counter and complementary to moral reasoning (Dedeke, 2015; Schwartz, 2016; Zollo et al., 2017a). However, the consumer ethics literature has paid scant attention to the intuitionist perspective. Some scholars theorize that emotions and automatic selfregulatory mechanisms predict ethical decisions (Chowdhury, 2017a; Sekerka and Bagozzi, 2007), but only a few have empirically demonstrated that intuition precedes pro-environmental attitudes and intentions (Zollo et al., 2018).

The literature has at least three limitations. First, it fails to provide theoretically grounded research to show how emotions and intuition interact to affect moral

\footnotetext{
${ }^{1}$ Business ethics and management scholars provide unclear and scattered definitions of emotion and intuition. Gaudine and Thorne (2001, p.176) state that the boundaries among emotions, moods, and affective personality traits are "unsharp," but emotions are more intense, shorter-lasting, and related to the environment. However, the Oxford English Dictionary provides one of the most acknowledged definitions of emotion as a "strong feeling deriving from one's circumstances, mood, or relationships with others" and an "instinctive or intuitive feeling as distinguished from reasoning or knowledge" (https://en.oxforddictionaries.com/definition/emotion). Hence, the "social" relationship and the non-rational intuitive components clearly emerge. Dane and Pratt (2007, p.34) argue that intuition has many associated terms, including "gut feelings...hunches... and mystical insights". For our purposes, the most significant definition is "thoughts and preferences that come to mind quickly and without much reflection" (Kahneman, 2003, p.697) and "a cognitive conclusion based on ... previous experiences and emotional inputs" (Burke and Miller, 1999, p.92). Thus intuition is quick, effortless, non-rational, and directly related to emotions (Haidt, 2001; 2003).
} 
reasoning and behavior (Chowdhury, 2017b). For example, arousal and feeling states have been shown to affect ethical decisions in the workplace (Gaudine and Thorne, 2001), but the rationalist perspective largely neglects unconscious emotional processing and intuition (Haidt, 2001; 2003; Tangney et al., 2007a). Actually, nonrational elements such as moral emotions and affect-laden intuitions are antecedents and predictors of ethical consumption decision making (Chowdhury, 2017a; Yacout and Vitell, 2018), so more emphasis should be placed on how those cognitive factors motivate ethical consumption. Second, the current literature (Zollo et al., 2017a; 2018) has mainly focused on the micro level of individual thinking, which represents only the "intuitionist" part of Haidt's (2001) model. As a result, missing is a conceptualization of how one consumer's ethical decisions might persuade and influence other consumers' moral judgments and ethical behavior, representing the "social" part of the social intuitionist model (Haidt, 2001; 2003). However, if we applied the whole social intuitionist framework to a managerial context, we could analyze how persuasion and social influence ${ }^{2}$ are linked to impact ethical decision making (Albert et al., 2015). As "social actors" (Solomon, 1983), ethical consumers belong to interdependent social groups through which they self-construct collective identities (Cherrier, 2007; Kim and Johnson, 2013). Hence, persuasion, cognitive association, mimicry, and social influence highly affect consumer behavior (Argo et al., 2005; Kulesza et al., 2014). Researchers and practitioners would gain significant insights from a theoretical investigation of both rational and nonrational cognitive mechanisms to explore persuasion and social influence in ethical consumption. Indeed, decisions, behaviors, and experiences of social/reference "normative others" (Shaw and Clark, 1999) such as family, friends, peers and colleagues have been shown to

${ }^{2}$ Robert B. Cialdini, one of the most influential psychologists on the topic, has widely studied persuasive mechanisms in social interactions (Cialdini, 2001). Among the main principles explaining persuasion and the resulting social influence, reciprocity (Zollo et al., 2017b, liking (Cialdini, 2001), and social consensus (Jones, 1991) are most relevant to our work. 
significantly influence sustainable consumption such as biodegradable product purchases, recycled packaging usage, and reduced energy usage (Salazar et al., 2013). Finally, consumer behavior (Argo et al., 2005; McFerran et al., 2009; Tanner et al., 2008) and business ethics scholars (Chowdhury, 2017b; Sekerka and Bagozzi, 2007) have usually used psychological theories to propose frameworks regarding consumers' ethical decision making and behavior, but have neglected interdisciplinary perspectives and holistic models from other domains (Shaw et al., 2016b). Yet, considering that ethical consumption relates to complex and multifaceted social, relational, and cultural considerations, the literature might benefit by considering collective and human social interactions, such as occurs in microsociology (Dahl, 2013; Solomon, 1983), which studies how individuals interact and recognize one another. Thus "a dialogue between psychology and microsociology is fundamental for establishing the bridge between internal and external worlds" (Islam, 2019, p.2).

Building on social intuitionist theory (Haidt, 2001; 2007), we address the gaps by proposing a holistic and integrated conceptual framework that theorizes emotions and intuition as antecedents of consumers' moral reasoning and behavior. The proposed framework advances integrated ethical decision making models (Dedeke, 2015; Schwartz, 2016) and ethical consumption (Chowdhury, 2017a; Vitell et al., 2003) by theorizing (1) how intuitive moral judgments unconsciously influence ethical decision making; and (2) how moral emotions crucially affect persuasion and social influence among ethical consumers. We extend Haidt's (2001) social intuitionist model by examining how ethical consumption depends on interpersonally engaging, "otheroriented" moral emotions such as elevation, gratitude, and empathy (Haidt, 2003; Tangney et al., 2007b) and affectively charged intuitive judgments (Zollo et al., 2017a). Moreover, the sociological perspective of symbolic interactionism (Mead, 1934) complements social intuitionist theory by conceptualizing ethical consumers as 
socially embedded agents (Solomon, 1983) acting in accordance with social interactions and perceptions of other consumers' judgments and behaviors (Blumer, 1969; Langer, 1978). Although consumer behavior scholars have considered symbolic interactionism (Dahl, 2013), ethical consumption research has largely ignored the perspective, despite potential contributions to both scholars and practitioners.

Next, we introduce the theoretical background by reviewing relevant studies. Then we present the social intuitionist framework of consumers' ethical decision making, along with propositions highlighting innovative insights for consumer ethics researchers and managers interested in ethical consumption. We conclude by stressing the theoretical and practical implications and making suggestions for future research.

\section{Ethical consumption}

Ethical consumers are increasingly recognized as groups ${ }^{3}$ of socially and environmentally responsible individuals who avoid patronizing unethical companies (Harrison et al., 2005) and choose consumption experiences (Cherrier, 2007; Cherrier and Murray, 2007) according to ethical concerns which result in ethical beliefs (Vitell et al., 1991). Thus, ethical consumption has been seminally defined as "the degree to which consumers prioritize their own ethical concerns when making product choices" (Shaw and Clarke, 1999, p.163). This "dollar voting" (Shaw et al., 2006) is the process of avoiding companies involved in "human rights violations, exploitative labor relations, uneven land rights, environmental degradation, irresponsible marketing, unfair trade, nuclear power, armaments proliferation, animal testing, factory farming" (Zollo et al., 2018, p.693), while supporting socially responsible companies. Scholars

\footnotetext{
${ }^{3}$ Ethical consumers are interpreted as a specific group (Shaw and Clark, 1999), a social movement with group consciousness (Cherrier, 2007) valuing environmental, wildlife, and ethical issues and disdaining oppressive, warring regimes (Shaw et al., 2006). Accordingly, scholars used self-construal theory to define ethical consumers as strongly interdependent and defined through their relationship with a social group (Kim and Johnson, 2013). Social identity theorists conceptualized a social group as "a number of individuals who have internalized the same social category membership as a component of their self concept" (Turner, 1982, p.36). Indeed, individuals with highly interdependent self-construal deeply value interconnectedness and are more motivated to fulfill obligations to their most primary interpersonal group relationships.
} 
(Carrington et al., 2016; Chowdury, 2017a; Shaw and Clarke, 1999; Vitell et al., 2013) have widely studied factors influencing consumer ethics - "the moral principles and standards that guide the behaviour of individuals and groups as they obtain, use and dispose of goods and services" (Muncy and Vitell, 1992, p.292). As a result, ethical consumption mostly results from consumers' self-construal regarding identity, ideology, values, and personality (Cherrier and Murray, 2007; Kim and Johnson, 2013). In other words, consumers may choose ethical consumption to express their personal ethical values and beliefs (Cherrier, 2007). To be aligned with the prevailing ethical consumption culture, managers focus on how consumers perceive, judge, and act on company reputations and brand identities and companies must align their conduct, services, and products with consumers' ethical beliefs to safeguard and sustain competitiveness (Zollo et al., 2018).

In summary, ethical consumption and consumers' ethical beliefs work together. Inner cognition forms the basis for self-identity; ethical decision making processes form the basis for social, collective identity (Cherrier, 2007). Despite those understandings, the literature has paid scant attention to the inner and relational antecedents and predictors of ethical decision making (Yacout and Vitell, 2018). We align our thinking with Chatzidakis et al. (2018) and use an interdisciplinary perspective for considering socio-cognitive (Cherrier, 2007; Cherrier and Murray, 2007) and socially oriented approaches (Connolly and Prothero, 2008; Shaw and Clarke, 1999; Solomon, 1983), to better understand the internal and external factors influencing how consumers make ethical decisions. The socio-cognitive approach requires consideration of both rational and unconscious elements, specifically the complementary part of moral reasoning named moral intuition, seminally defined as "the sudden appearance in consciousness of a moral judgment, including an affective valence (good-bad, like-dislike), without any conscious awareness of having gone through steps of searching, weighing 
evidence, or inferring a conclusion" (Haidt 2001, p.818). The socially oriented approach conceptualizes consumers as socially embedded agents who make ethical consumption decisions based on social rules, roles, and information (Shaw et al., 2016a; Solomon, 1983).

Hence we contribute to the theoretical debate about (1) the socio-cognitive approach that considers cognitive components that precede and influence consumers' ethical decision making, and (2) the socially oriented approach that considers affective persuasion and social influences among ethical consumers.

\section{The socio-cognitive approach of ethical decision making}

The rationalist perspective

Ethical decision making is "a process by which individuals use their moral base to determine whether a certain issue is right or wrong' (Carlson et al., 2009, p.536). Applying Jones's (1991) issue-contingent model to ethical consumption, consumers are moral agents behaving according to their personal morality. They face moral issues when their decisions or behaviors may have positive or negative consequences for others. Traditionally, ethical decision making was considered in terms of cognitive moral development (Rest, 1986), moral issues/intensity (Jones, 1991), and situational/environmental/cultural factors (Ferrell and Gresham, 1985; Hunt and Vitell, 1986). All the models share a rational cognitive perspective in which ethical decision making is conscious, deliberative, intentional, and individually controlled.

The most widely acknowledged rationalist framework is the four-component model (Rest, 1986), which argues that the first phase of ethical decision making is moral awareness, in which the consumer recognizes a moral issue and identifies positive or negative consequences (Jones, 1991). From a rationalist perspective, moral awareness is activated when consumers perceive the "moral intensity" (Carlson et al., 2009) of 
ethical dilemmas. The second phase is moral judgment, when moral principles and values are crucial as consumers assess whether an issue is "good" or "bad," and evaluate possible behaviors and resulting consequences (Jones, 1991). The third phase is moral intent, in which consumers prioritize their moral principles and values to decide the appropriate behavior and assume responsibility for moral consequences (Carlson et al., 2009). This phase reveals whether moral principles are strong enough to motivate actual ethical behavior. The fourth phase is moral behavior, in which the consumer performs actions consistent with moral intent, the "ultimate test" of ethical behavior in which the individual must cope with impediments, complications, fatigue, and frustration (Zollo et al., 2017a). In other words, consumers who morally persevere will avoid the common "attitude-behavior" ethical consumption gap (Carrington et al., 2016; Caruana et al., 2016; Shaw et al., 2016a). The four phases constitute moral reasoning (Rest, 1986), in which consumers "intentionally rationalize, re-evaluate, and justify, moral standards, rules of conduct, and moral life" (Zollo et al., 2018; p.694). Therefore, moral reasoning is used to rationalize ethical decisions and to legitimize moral practices and ethical lifestyles (Sonenshein, 2007).

To analyze moral reasoning, marketing scholars have traditionally followed the general theory of marketing ethics (Hunt and Vitell, 1986), which explains that consumers use deontological evaluations to compare alternative behaviors and teleological evaluations to determine consequences. In addition, scholars have focused on the contingency framework (Ferrell and Gresham, 1985) to explain that sociocultural norms, ethical beliefs, and values held by significant others are contingencies affecting ethical decision making. However, those perspectives are primarily rationalist and mainly focus on single individuals. They did not fully consider that moral judgment and behavior can be formed by emotions, intuition, persuasion and social influences. 
Figure 1 is an illustration of a comprehensive rationalist framework.

Insert Figure 1 Here

\section{The intuitionist perspective}

Scholars are increasingly realizing that the dominant rationalist frameworks fail to fully account for actual ethical behavior (Chatzidakis et al., 2018; Vitell et al., 2013; Yacout and Vitell, 2018). By considering consumers as fully rational and conscious decision makers, rationalist models overestimate explicit reasoning, although social environments can be equivocal and uncertain (Shaw and Clarke, 1999; Sonenshein, 2007), so that non-rational elements, such as emotions and intuitions, affect perceptions, moral judgment, and intent (Chowdhury, 2017a; Sekerka and Bagozzi, 2007). Consequently, consumer ethics research must consider an affective-intuitionist perspective to identify nonconscious, unintentional, and nondeliberative cognitive mechanisms impacting ethical consumption (Zollo et al., 2018), with a focus on "more intuitive approaches," particularly considering "values, emotions, and intuitive responses" (Cherry and Caldwell, 2013, p.117).

The dual processing theory of human cognition (Evans, 2008; Kahneman, 2003) opposes the traditional conscious-reasoning perspective and instead suggests the intuitionist perspective highlighting moral intuition as an automatic, reflexive antecedent of moral judgment and moral reasoning (Haidt, 2001; Sonenshein, 2007). The intuitionist theory suggests that moral intuition plays a primary role in generating moral judgment; moral reasoning plays a subsequent role when individuals evaluate decisions they formed subconsciously (Haidt, 2001). The well-known theory of System 1 and System 2 also argues that human cognition has two information processing systems (Evans, 2008; Kahneman, 2003). System 1, the "experiential system," is 
intuitive, rapid, reflexive, automatic, and instinctive. System 2 is controlled, slow, reflective, logical, and analytic reasoning. The two systems are parallel, simultaneous, and complementary, indicating "two minds in one brain" (Evans, 2008, p.268). The systems framework can be applied to the theory of social and moral judgment: moral intuition fits as a System 1 automatic, spontaneous, impulsive, and quick process; while moral reasoning fits as a System 2 deliberative, conscious, reflective, and slow process (Zollo et al., 2017a).

\section{The social intuitionist perspective}

Consistent with dual processing theory, the social intuitionist model (Haidt, 2001) is one of the most widely acknowledged frameworks emphasizing moral intuition as primary in ethical decision making (Evans, 2008; Kahneman, 2003). Moral intuition involves emotional affect underlying intuitive moral judgment and ethical decision making ${ }^{4}$ (Greene et al., 2001; Haidt, 2003). The renowned metaphor of the "emotional dog" (moral intuition) and the "rational tail" (moral reasoning) is a way to visualize the process: emotions and intuitions play an a priori role in forming affect-laden intuitive moral judgments and are therefore an antecedent of post hoc moral reasoning (Haidt, 2001). Table 1 provides a taxonomy of the affective-intuitionist perspective.

\section{Insert Table 1 Here}

Moral intuition includes two cognitive phases. The first phase is intuiting (Dane and Pratt, 2007) and fits with System 1 as a fast, automatic, and reflexive nonconscious

\footnotetext{
${ }^{4}$ Moral intuition differs from heuristics, which are subconscious shortcuts that rely on past experiences for solving similar problems (Haidt, 2001; 2005). Affect heuristics indicate automatic gut feelings that can be misleading for solving moral dilemmas because they often result from cultural prejudice rather than moral principle (Zajonc, 1980). For example, when thinking about "abortion, euthanasia, cloning, or any other difficult issue" (Haidt, 2005, p.553), reliance on past experience or previous moral deliberations might deviate intuitive moral judgment. "The moral domain is a weird and treacherous world in which objects change their weights and rivers flow uphill. Or at very least, minds that worked in one way on non-moral problems suddenly start working differently when moral concerns are introduced" (Haidt, 2005, p.552). Hence, heuristics based on previous experiences might impact on moral intuition and affect-laden intuitive moral judgment, but moral intuition is primary for ethical decision making (Haidt, 2001).
} 
cognitive process. Intuiting allows decision makers to unconsciously and holistically elaborate external stimuli to make rapid and intuitive judgments when facing dynamic, uncertain, and fast-changing situations requiring immediate cognitive holistic associations (Dane and Pratt, 2007). The second phase is emotional processing (Evans, 2008; Greene et al., 2001; Kahneman, 2003), the affective component, the experiential state, the emotional unconscious, the "hot emotive system" within the moral intuition process (Zollo et al., 2017a, p.687). Emotional processing aligns with Metcalfe and Mischel (1999) who compare the "hot emotional system" with the "cool cognitive system". Basic emotions (i.e., happiness, sadness, anger, and surprise) fit with System 1 and arise quickly, effortlessly, and subconsciously (Haidt, 2001). More complex emotions (i.e., desire, disgust, and jealousy) fit with System 2, the deliberative and rational system of moral reasoning (Greene et al., 2001; Haidt, 2003). Thus emotional processing capacities greatly influence intuitive moral judgments and the ability to make ethical decisions (Zollo et al., 2017a). In other words, intuitive information processing largely depends on emotions and is strongly affectively charged (Greene et al., 2001).

Overall, moral intuition includes both intuiting and emotional processing. Consequently, affect-laden intuitions underlie ethical decisions and intuitive moral judgments a priori; moral reasoning provides the post hoc rationalizations (Haidt, 2001). Figure 2 illustrates a dual processing model of ethical decision making, including both moral intuition (System 1) and moral reasoning (System 2).

Insert Figure 2 Here

Moral emotions 
Moral emotions are "linked to the interests or welfare either of society as a whole or at least of persons other than the judge or agent" (Haidt, 2003, p.853). Moral emotions cause consumers to care about others' actions and can explain individual choices between good or bad behaviors (Kim and Johnson, 2013). Indeed, "Moral emotions provide the motivational force - the power and energy - to do good and to avoid doing bad" (Tangney et al., 2007a, p.347). Most relevant to our purposes is that moral emotions differ from other emotions. First, "disinterested" elicitors such as others" triumphs/successes or tragedies/transgressions are the triggers for moral emotions. Hence, the self has no stake in the eliciting events, differently for example from fear and happiness occurring in reaction to good or bad events happening to the self. Second, moral emotions motivate the consumer to adopt prosocial actions that benefit others or the social order (Haidt, 2003).

Moral emotions fall into four main categories: (1) "other-condemning" emotions of contempt, righteous anger, and disgust; (2) "self-conscious" emotions of shame, embarrassment, guilt, and moral pride; (3) "other-praising" emotions of gratitude and elevation; and (4) "other-suffering" emotions of empathy (Haidt, 2003, p.855). On the "negative" side, contempt, righteous anger, and disgust are negatively valenced otheroriented moral emotions; shame, embarrassment, and guilt are negatively valenced self-oriented moral emotions (Tangney et al., 2007a, p.357). On the "positive" side, moral pride is a positively valenced self-oriented moral emotion; gratitude and elevation are positively valenced other-oriented moral emotions (Tangney et al., 2007a; b). Finally, empathy - also called sympathy or compassion (Haidt, 2003, pp.861-862) - is a morally relevant other-oriented emotional process that substantially motivates prosocial action tendencies (Tangney et al., 2007a; b).

Spontaneous/automatic perceptions of events and subsequent feelings tend to elicit other-oriented moral emotions, while cognitive appraisals and consequent 
interpretations tend to elicit self-oriented moral emotions (Haidt, 2003; Tangney et al., $2007 a$; b). Hence, other-oriented moral emotions are related to the "hot emotional system" of System 1 and self-oriented moral emotions are related to the "cool emotional system" of System 2 (Metcalfe and Mischel, 1999). Indeed, the selfconscious moral emotions - shame, embarrassment, guilt, and moral pride - "arise when reflecting on one's self and evaluating that self in reference to values and standards" and are thus interpreted as "rich, complex, and higher-order emotions" (Tangney et al., 2007b, p.21). Instead, the other-oriented moral emotions comprising contempt, righteous anger, disgust, gratitude, and elevation are usually considered automatically expressed "basic" emotions 5 (Tangney et al., 2007a; b).

Building on those understandings, we focus on gratitude, elevation, and empathy because they motivate the highest prosocial action tendencies (Haidt, 2003, p.854) and are other-oriented, "interpersonally engaging" moral emotions (Kim and Johnson, 2013, p.81) that might significantly motivate moral actions in reaction to the moral behavior of others (Haidt, 2000; 2003; Tangney et al., 2007b). Actually, the proposed social intuitionist framework focuses on unconscious emotive and intuitive cognitive mechanisms that form affective persuasion and social influence aimed at ethical consumption, so other-oriented moral emotions and emotional processes such as elevation, gratitude, and empathy are relevant for observing the persuasive mechanisms.

Other-oriented moral emotions in ethical decision making: elevation, gratitude, and empathy

\footnotetext{
${ }^{5}$ Empathy, which fits into the other-suffering category, has a dual nature depending on its specific sub-component as described in the following section. In fact, empathy has both an affective (System 1) and cognitive (System 2) component (Eisenberger et al., 2004; Shamay-Tsoori et al., 2009; Smith, 2006; Tangney et al., 2007a).
} 
Elevation is a positively valenced moral emotions that arises in response "to good deeds and moral exemplars" (Haidt, 2003, p.862). For example, individual B observes that individual A is a "moral exemplar" (Tangney et al., 2007a) who acts ethically and virtuously. As a result, B feels elevation (Haidt, 2000), a quintessential positive emotion evoking pleasant, positive feelings motivating B to emulate the altruistic and prosocial behavior (Haidt, 2003). Applied to the dual processing model of ethical decision making (Zollo et al., 2017a), A's moral behavior evokes elevation in B's “emotional unconscious" and increases B's affect-laden intuitions (Haidt, 2000; 2003; Tangney et al., 2007a).

Another positive moral emotion is gratitude that occurs when individuals receive benefits from another person, especially when benefits are "unexpected and/or costly to the benefactor" (Tangney et al., 2007a, p.362). Gratitude is related to reciprocal altruism (Zollo et al., 2017b) motivating (moral intent) moral behavior. Hence, when A provides benefits to B, B feels gratitude and wants to repay A through prosocial actions (Haidt, 2003; Tangney et al., 2007a).

Finally, empathy "stems from another's emotional state or condition and is congruent with the other's emotional state or condition" (Eisenberg et al., 2014, p.65). While indifference leads to moral disengagement in which individuals "suspend selfregulatory processes that prevent unethical behavior" (Chowdhury and Fernando, 2014, p.678), empathy has both affective and cognitive components (Tangney et al., 2007a). When individuals personally experience the emotions of others, they react with affective, emotional empathy (Tangney et al., 2007a), a "vicarious sharing of emotions" (Smith, 2006, p.3). Affective empathy is basic to the emotional contagion system that supports "our ability to empathize emotionally ('I feel what you feel')" (Shamay-Tsoory et al., 2009, p.617). In contrast, cognitive empathy indicates "mental perspective taking" (Smith, 2006, p.3) occurring when individuals take the perspective 
(moral awareness) of others and then understand (moral reasoning) their emotional experiences (Eisenberg et al., 2014). Hence, cognitive empathy allows mentalizing others' perspectives ('I understand what you feel') (Shamay-Tsoory et al., 2009, p.617).

Applied to the dual processing model of ethical decision making, perceptions of others' moral behaviors trigger affective empathy that activates intuitive moral judgment; perceptions of others' emotional needs triggers cognitive empathy that motivates prosocial efforts to help and comfort (Haidt, 2003).

\section{Toward a social intuitionist approach of ethical consumption}

Business ethics scholars have used the intuitionist perspective to theorize integrated models of ethical decision making. Woicheshyn (2011), for example, highlighted parallel and interacting processes of the two systems and identified a "spiraling process" between the subconscious/intuitive/reflexive system (the X-System) and the conscious/rational/reflective system (the C-System). Consistently, Dedeke (2015) and Schwartz (2016) conceptualized cognitive-intuitionist models interpreting emotion and intuition as cognitive processes influencing the relationship between moral awareness and moral judgment. More recently, Zollo et al. (2017a) applied Haidt's (2001) theory to propose an intuitionist model interpreting moral intuition as a System 1 process forming a priori affect-laden intuitive moral judgments. Moral reasoning (a System 2 process) then rationalizes and re-evaluates moral judgments, post hoc. However, the authors' theoretical propositions did not consider that social influences and persuasions may have unconscious effects on other decision makers, nor did they consider the specific role of moral emotions.

Despite the growing research, consumer ethics studies have widely neglected the affective-intuitionist perspective. Consequently, we need more research on the 
emotional and intuitive factors affecting moral judgment and behavior (Chowdhury, 2017a). Vitell et al. (2013) argued that emotional states impact consumers' moral judgment, moral intent, and moral behavior, aligning with a theoretical model in which affective reactions and ethical values are theorized as antecedents of ethical choices (Sekerka and Bagozzi, 2007). Accordingly, emotional intelligence (Chowdhury, 2017a) and empathy (Chowdhury and Fernando, 2014) have been found to significantly influence consumers' ethical beliefs. Zollo et al. (2018) built on Haidt's (2001) framework and the TPB (Ajzen, 1991) to empirically show that moral intuition (System 1) significantly impacts pro-environmental attitudes and ethical behavioral intentions (System 2). Yet the authors failed to consider that a single consumer's ethical decisions might affect other consumers' social interactions and interpersonal persuasions, nor did they consider how moral emotions might affect such interactions.

Overall, those studies were microanalyses that considered "inner" ethical decision making of consumers, the "intuitionist" part of Haidt's (2001) model. Thus, business ethics and ethical consumption studies have neglected the "social" part of the model which refers to affective persuasion and social influence coming from others. To fill the gap, we blend the social intuitionist perspective (Haidt, 2001) with the microsociological approach of symbolic interactionism (Mead, 1934). We propose an integrated and holistic conceptual model showing that inner emotive and intuitive cognitive mechanisms lead to moral judgments but that consumers' moral emotions and intuition also influence other consumers' ethical decisions.

\section{The socially oriented approach}

Individuals are socially embedded, born into social rules and institutions such as language and marriage that both constrain and enable their lives (Shaw et al., 2016b). 
Consumption is also "fundamentally embedded in social relations" (Connolly and Prothero, 2008, p.125) as consumers act as social actors aligned with their social roles and relying on social information to shape and define their self-image (Solomon, 1983). Consequently, to enhance their images and identities and gain social approval, they strive to meet expectations of significant others by acquiring and using products and brands that signal their conformance to social expectations and preferences (Childers and Rao, 1992). Thus social interactions ${ }^{6}$, social experiences, and collective participation affect the construction of consumers' self-identities (Belk, 1988; Cherrier, 2007) and behavior (Argo et al., 2005; McFerran et al., 2009). Significant or "normative" others (Shaw and Clarke, 1999) such as families, partners, children, colleagues, the state, and the market contribute to the construction of "quintessentially social and intrinsically relational" consumer identity (Cherrier, 2007, p.5). Therefore, researchers and practitioners must understand how persuasion and social influences affect consumption.

\section{Consumers as interdependent and socially embedded agents}

Humans strongly tend "to align their behavior with their fellows during social interactions" (Iacoboni, 2009, p.657) in pervasive, automatic, complex forms of imitation and mimicry (Chartrand and Bargh, 1999). These forms include anchoring and adjustment (McFerran et al., 2009), mimicry and the "chameleon effect" (Kulesza et al., 2014; Tanner et al., 2008), and cognitive association (Argo et al., 2005). When making food choices, consumers have been shown to anchor their consumption quantity decisions on decisions of others (McFerran et al., 2009). Anchors are

\footnotetext{
${ }^{6}$ Building on social impact theory, Argo et al. (2005, p.207) empirically demonstrated that both interactive and noninteractive social presence (i.e., "a mere presence") can influence consumption behavior. Beyond physical presences or live interactions, individuals still have opportunities to mimic others' behavior, such when they observe another customer shopping nearby (Tanner et al., 2008, p.755), with impacts on their moral decisions. As a result, ethical consumers might seek belongingness and collective participation (Cherrier, 2007) without being engaged with other consumers.
} 
cognitive biases that dominate decision making inducing to excessively rely on initial information and serve as reference points for creating social norms for making quality and quantity decisions (McFerran et al., 2009). Another type of social influence is automatic behavioral mimicry, the unconscious and unintentional tendency to mimic others in social contexts (Tanner et al., 2008). Mimickers may believe that they are acting according to their personal preferences, but they may actually be guided by nonconscious mimicry of others, which may explain that people shift their behaviors and preferences (Tanner et al., 2008) because they are persuaded by mimicry associated with prosocial behavior (van Baaren et al., 2004). The mere act of mimicking may cause inadvertent interpersonal persuasion in that mimickers form positive emotions and unconscious prosocial reactions toward the mimicker (Tanner et al., 2008). The phenomenon clearly resembles the "chameleon effect" (Chartrand and Bargh, 1999), through which individuals spontaneously, automatically, and unconsciously tend to mimic the behavior of others in their social surroundings (Haidt, 2001; Kulesza et al., 2014). Applied to consumer behavior, this automated and immediate social perceptual activity directly influences preferences (Kulesza et al., 2014; Tanner et al., 2008). Similarly, cognitive association theory posits that people rely on automatically elicited inferences to make social judgments, even when they casually observe the behaviors and without social engagement (Argo et al., 2005), and especially when sharing similar attitudes or values (McFerran et al., 2009). The inferential associative process is characterized by an initial "trait activation" during which consumers perceive and interpret others' behavior. Next follows 'trait association" during which consumers want to relate to similar others. Finally, "trait influence" occurs when consumers are persuaded to imitate similar others' decision making and consumption behavior (Argo et al., 2005). The "liking" principle (Cialdini, 2001) is one of the main explanatory mechanisms; that is, individuals tend 
to form prosocial attitudes toward similar others, to like them, to agree with them, and to be persuaded by them.

Overall, the literature frames consumers as social agents (Solomon, 1983) embedded and acting within "institutionalized" consumption practices (Cherrier, 2007), affected by the social norms, rules, relations, structures, and culture characterizing their socioeconomic environment (Shaw et al., 2016a). Hence, the socially oriented approach (Chatzidakis et al., 2018) will prove beneficial to the ethical consumption literature (Carrington et al., 2016; Cherrier, 2007).

\section{Social influence, identity and interaction in ethical consumption}

Particularly relevant for studying ethical consumption is the socially oriented approach (Chatzidakis et al., 2018), which traditionally identified ethical consumers as an interpersonal "social group" sharing a specific social consensus ${ }^{7}$ that defines their selfidentity (Cherrier and Murray, 2007; Kim and Johnson, 2013). Further building on the interpersonal approach, ethical decision making scholars argue that both self-identities and social consensus are moderators of cognitive processes regarding ethical issues (Albert et al., 2015). Indeed, normative others in an individual's social sphere are thought to influence behavioral beliefs (Cherrier and Murray, 2007; Shaw and Clarke, 1999). Thus ethical consumers are "socially embedded individuals" behaving in an institutionalized context of social rules and norms that influence their ethical identity (Carrington et al., 2016; Cherrier, 2007; Shaw et al., 2016a). For example, to selfconstruct their identities, ethical consumers might purchase products or services that reflect their moral beliefs, principles, and values.

\footnotetext{
${ }^{7}$ Social consensus is defined as "social agreement that a proposed act is evil (or good)" (Jones, 1991, p.375). That is, individuals
} are motivated to act morally and prosocially when their referent others favor the actions (Albert et al., 2015). 
Accordingly, self-construal theory has been widely used to assess individual perceptions of their relationships with themselves and others; especially, their feelings of being separated or connected (Kim and Johnson, 2013). Individuals who tend toward independent self-construal define themselves as individual entities and tend to come from individualistic cultures; in contrast, those who lean toward interdependent self-construal define themselves in the context of relationships and group memberships, in accordance with social norms, group membership, and others' opinions, and tend to come from collective cultures (Kim and Johnson, 2013). Consequently, consumers might choose ethical consumption to self-construct their social identity (Belk, 1988), to show who they are, who they want to be, and how they want to "appear" within their interpersonal relationships (Cherrier, 2007). Ethical goods then become a social symbol for expressing consumption identities (Belk, 1988). When consumers are aware that products and services present ethical dilemmas, they may choose to avoid such products to remain consistent with their ethical identity (Harrison et al., 2005). Ethical consumption practices allow consumers to share their emotions and passion, express their self-identity, and act according to the "moral climate", "collective identity", and "common cognitive framework" (Cherrier, 2007, p.12) characterizing their social reality (Belk, 1988). Because "moral decisions are socially embedded and have strong relational dimensions" (Chatzidakis et al., 2018, p.5), ethical consumers are susceptible to referent others' perceptions and inferences regarding their behavior (Argo et al., 2005; Childers and Rao, 1992; McFerran et al., 2009). To signal their moral personality and character, they will act according to feedback and perceptions of significant/normative others (Cherrier and Murray, 2007; Shaw and Clarke, 1999). Hence, consumption practices acquire symbolic meaning in dynamic social interactions (Langer, 1978). 
Although psychological approaches are the main consideration in studying how ethical consumers influence, are persuaded, and interact with others, microsociology is another perspective that can enrich the literature (Islam, 2019). We apply the theory of symbolic interactionism (Blumer, 1969; Mead, 1934) to theoretically investigate how social interactions influence ethical decision making and ethical consumption.

\section{Symbolic interactionism}

Symbolic interactionism is a sociological theory originally conceived by George Herbert Mead (1934) and Charles Horton Cooley (1902). Herbert Blumer (1969), one of Mead's most renowned disciples, devised the most frequently cited conceptualization of symbolic interactionism, summarized according to three core principles: (1) people ascribe meanings to actions and to others and act accordingly; (2) meanings are derived through social interactions; and (3) meanings are formed through interpretive processes. Individuals, as social agents, thus create self-concepts and self-identities through symbolic meanings and perceptions of feedback and responses from group members with whom they interact (Langer, 1978). Such interpretive processes and symbolic meanings shape perceived social reality regarding social actors, social roles, and social information (Belk, 1988). Symbolic interactionism was seminally applied to consumer behavior and defined as "the process by which individuals understand their world" (Solomon, 1983, p.320), assuming that consumers interpret rather than simply react to others' actions, depending on the meaning and symbols they attach to the action (Blumer, 1969). Thus the symbolic environment mediates individual relations with physical (objective) reality (Mead, 1934). One of the major contributions of social interaction theory is that consumers' self-identity and self-image are predominantly formed through social 
interactions and relationships (Solomon, 1983), especially their perceptions of how others evaluate their behavior.

The theory of the "looking-glass self" 8 explains that individuals compose their selfidentity according to how they believe they appear to others, which can lead, for example, to feelings of pride or mortification (Cooley, 1902). The "seeing yourself as others see you" principle (Solomon, 1983, p.321) indicates that self-images and roles are partly determined by "estimates of how others are evaluating oneself". In social psychology terms, people seek uniform behavior and "attitudinal alignment"" according to their favored peers and reference-group members (Davis and Rusbult, 2001). In consumption terms, consumers act according to how they think others see them (Dahl, 2013; Solomon, 1983). Mead's and Cooley's theories are similar to automatic behavioral mimicry (Tanner et al., 2008) in suggesting that prosocial empathy, meaning the ability to imagine how others feel and inadvertently take the role of the other (Solomon, 1983, p.321), is one of the main drivers when consumers behave according to others' predicted behavior. Moreover, empathetic social interactions are often unconscious and automatic, especially in familiar social situations (Langer, 1978). That is why affective empathy, an important other-oriented emotional process (Haidt, 2003; Tangney et al., 2007a), is a major focus for our study. Although symbolic interactionism is an essential socialization mechanism, the ethical consumption literature has largely neglected the theory. Next, we present a comprehensive conceptual model of consumers' ethical decision making building on Haidt's (2001) social intuitionist framework and Mead's (1934) symbolic interactionism.

\footnotetext{
8 "I am not who you think I am; I am not who I think I am; I am who I think you think I am" (Cooley, 1902).

${ }^{9}$ Attitude alignment theory indicates that "the perceived associations among a perceiver $(p)$, another person $(o)$, and an attitude object $(x)$ tend to be consistent (or balanced), such that (a) if $p$ likes $o$, p feels comfortable when $p$ and $o$ hold similar attitudes about $x$ and (b) if $p$ dislikes $o, p$ feels comfortable when $p$ and $o$ hold different attitudes about $x$ " (Davis and Rusbult, 2001, p.66).
} 


\section{Theoretical framework and propositions}

A social intuitionist framework of consumers' ethical decision making

To contribute to growing research on integrated ethical decision making (Dedeke, 2015; Schwartz, 2016), we build on social intuitionist theory (Haidt, 2001) and symbolic interactionism (Blumer, 1969; Mead, 1934) to present the social intuitionist framework of consumers' ethical decision making (Figure 3). Aligned with Haidt (2001), our holistic and integrated model is descriptive because it "describes how people actually make decisions, in contrast to normative decision making, which is about how people ought to make decisions" (Dedeke, 2015, p.440).

\section{Insert Figure 3 Here}

The model includes three major components. (1) The "intuitionist" component (links 1 and 2) considers individual, private ethical decision making. (2) The "social" component (links 3, 4, and 5) emphasizes social interactions and perceptions of others' judgments and behaviors. (3) The "moral emotions" component (links 6, 7, and 8) stresses affective persuasion and social influence.

\section{The intuitionist component}

Figure 3 shows link 1, the "intuitive judgment link" showing how "moral judgments appear in consciousness automatically and effortlessly as the result of moral intuitions" and link 2, the "post hoc reasoning link" showing how "moral reasoning is an effortful process, engaged in after a moral judgment is made, in which a person searches for arguments that will support an already-made judgment" (Haidt, 2001, p.817). 
The (1) "intuitive judgment link" includes intuiting and emotional processing, the first two phases that lead to intuitive moral judgments (Dane and Pratt, 2007; Greene et al., 2001). Moral intuition is an unconscious, affectively charged process, but affect-laden intuition enters conscious awareness (Dane and Pratt, 2007). In summary, moral intuition is the individuals' ability to perceive a moral issue and react simultaneously and unconsciously according to what seems most the appropriate moral principle in the situation (intuiting). Meanwhile, events activate emotions and experiential states (emotional processing), generating intuitive moral judgments that appear a priori when making ethical decisions (affect-laden intuitions) (Zollo et al., 2017a, p.688). Applied to the ethical consumption context, the link proposes that consumers' moral intuition is a reflexive/automatic process (System 1) that creates automatic, instinctive intuitive moral judgment, without the reflective/deliberative process (System 2) of moral reasoning (Sonenshein, 2007). Thus, we propose:

Proposition 1: Moral intuition forms rapid, unconscious, reflexive, and automatic affectively charged moral judgments.

The (2) "post hoc reasoning link" represents the intuitionist component of Haidt's (2001) model by stressing that fast, effortless moral intuition is the main antecedent of slow, effortful moral reasoning. To reiterate, the social intuitionist perspective questions the traditional rationalist frameworks that are mainly centered on moral reasoning (Vitell et al., 2003). Instead, moral intuition is crucial for forming moral judgments that will be post hoc processed by rationalizations and justifications of moral reasoning (Sonenshein, 2007). Hence, emotions and intuitions underlie affectdriven moral choices and extend to all facets of ethical consumption behavior (Chowdhury, 2017a; Vitell et al., 2013). Consumer ethics scholars agree that moral intuition is a significant antecedent of moral reasoning and that consumers use 
intuitive responses in forming moral attitudes toward ethical consumption (Cherry and Caldwell, 2013; Zollo et al., 2018). Nevertheless, the social intuitionist framework clearly recognizes that moral reasoning plays an important, deliberative, and rational role in strengthening or correcting moral intuition (Zollo et al., 2017a). Consequently, consumers are not "prisoners of their initial intuitions, unable to change their minds once they have taken a position" (Haidt 2003, p.197). Our model takes a blended and balanced perspective by considering emotional processing, intuiting, and moral reasoning. We propose:

Proposition 2: Moral intuition forms a priori intuitive moral judgments impacting moral reasoning which provides post hoc rationalization, re-evaluation, and justification of the ethical decision.

\section{The social and moral emotions component}

The second component of the model refers to the "social" dimension described by links 3, 4, and 5 (Figure 3), and is integrated with the "moral emotions" component (links 6, 7, and 8).

Reasoned persuasion in ethical decision making: the role of elevation and affective empathy

Link 3 is the "reasoned persuasion link", proposing that people form moral reasons for actions and then justify their reasoning verbally - through "moral discussions and arguments" (Haidt, 2001, p.819) - which then affects others. The "reasoned persuasion link" works similarly to anchoring and adjustment (McFerran et al., 2009) in that decisions of others and social norms serve as "anchors" (i.e., reference points) guiding purchase and consumption decisions. Then other consumers will observe those decisions and use them as anchors for rationally and intentionally choosing what 
and how much to consume (Argo et al., 2005; Dahl, 2013; McFerran et al., 2009). In the ethical consumption setting (link 3), A's reasoned persuasion depends on A's moral awareness, moral judgment, moral intent, and moral behavior (Rest, 1986) which then influence B's affective emotional processing and intuiting. Specifically, "reasoned persuasion works not by providing logically compelling arguments but by triggering new affectively valenced intuitions in the listener" (Haidt, 2001, p.819). As Figure 3 (link 6) shows, A verbally ${ }^{10}$ expresses the moral justifications for moral judgments or behaviors, eliciting B's elevation and affecting B's intuitive moral judgment (Haidt, 2000). As a result, B is affectively persuaded (elevated) and forms consequent moral reasoning (Haidt, 2001; 2003; Tangney et al., 2007a).

Theories of interpersonal relationship argue that in social contexts individuals will act as they think others are acting, especially in ethical decision making (Albert et al., 2015). The search for social consensus (Cialdini, 2001; Jones, 1991) is spontaneous and automatic and explains why consumers emulate the decisions and actions of others (Argo et al., 2005; McFerran et al., 2009). Therefore, when consumers interact socially, they will internalize cultural and personal symbols regarding their social status and social reality (Belk, 1988; Solomon, 1983). As "socially connected beings" (Caruana et al., 2016, p.215) ethical consumers share symbolic systems to selfconstruct complex and multiple consumption identities (Kim and Johnson, 2013). And this works thanks to a "unique property of humans", empathy (Solomon, 1983, p.321). Similarly, social psychologists (Iacoboni, 2009, p.659) argue that (1) the more people tend to imitate others, the more they are concerned about others' feelings; (2) empathy is strongly correlated with imitative behavior; (3) imitation and mimicry increase empathy by allowing people to feel what others feel and to respond compassionately

${ }^{10}$ Althoug A's moral reasoning is "produced and sent forth verbally" to express moral justifications (Haidt, 2001, p.819), A might persuade B as a noninteractive social presence in the consumption setting (Argo et al., 2005, p.211). Hence, B might read, watch, or learn about A's moral discussion and arguments with no direct interaction and still be affectively persuaded. 
to their emotional states (Chartrand and Bargh, 1999; Tangney et al., 2007a). Aligned with the psychological framework of moral emotions (Haidt, 2003), link 8a of the model represents the "empathetic mechanism" (Figure 3): A's moral behavior influences consumer B's affect-laden intuition through the affective empathy pathway (Eisenberg et al., 2014; Tangney et al., 2007a). Specifically, B personally experiences and shares A's moral condition or state. The resulting "congruent" intuitive moral judgment is emotionally contagious (Eisenberg et al., 2014, p.65). We propose:

Proposition 3: Consumer A's moral reasoning serves as an "anchor” to persuade consumer B's moral intuition and consequent intuitive moral judgment. Moral emotions such as elevation and affective empathy elicit consumer B's affect-laden intuitions thus provoking affective persuasion and social influence. The "anchors" acquire the value of symbolic meaning able to persuade moral consumer behavior consistent with a desired social role.

Social persuasion as an unconscious interpersonal mechanism in ethical decision making

Link 4, the "social persuasion link", is one of the most important elements in the social intuitionist model. People are highly attuned to group norms (Cherrier, 2007; Kim and Johnsons, 2013), so they are influenced by "the mere fact that friends, allies, and acquaintances have made a moral judgment", even without reasoned persuasion (Haidt, 2001, p.819). In other words, A's intuitive moral judgments significantly influence B's affect-laden intuitions. The cognitive mechanisms are unconscious, reflexive, and automatic (Evans, 2008; Kahneman, 2003), so the social persuasion link works within System 1 (Haidt, 2001). The social persuasion link works similarly to automatic behavioral mimicry (Tanner et al., 2008), a "nonconscious stereotyping" in which consumers automatically and spontaneously mimic decisions and behaviors of 
others (McFerran et al., 2009, p.927). Hence, A's intuitive moral judgments are a significant unconscious source of unaware preference for B (Tanner et al., 2008) and the mimicry mechanism ensures that they will trigger prosocial emotions and moral intuition, leading other consumers toward ethical behavior (van Baaren et al., 2004). Those observations are consistent with the symbolic interactionism notion of the “looking-glass self” (Cooley, 1902) discussed earlier. According to Solomon (1983, p.323), "Reflexive feedback that one 'looks the part' elicits the set of learned behaviors corresponding to the appropriate 'me', thus generating a self-fulfilling prophecy as others pattern their behavior vis-à-vis the enacted role". Hence, consumers need and desire to conform with social forces and group norms (Cherrier, 2007), particularly regarding ethical consumption (Shaw and Clarke, 1999). Thus, we propose:

Proposition 4: Moral intuition is an interpersonal persuasion mechanism leading other consumers to feel prosocial emotions and unconsciously mimic ethical decision making. Consumers will instinctively make ethical decisions that are consistent with the way they imagine other consumers will judge them.

Prosociality and reciprocity in ethical decision making: the role of gratitude and cognitive empathy

Link (5), the "prosocial link", is consistent with social intuitionist theory (Haidt, 2001; 2003) in representing a "feedback loop" in which B's moral reasoning positively affects A's moral intuition. In other words, consumers' moral intuition is enhanced when they see that they are persuading others to adopt their attitudes and behaviors. The loop occurs because of the other-oriented moral emotion of gratitude (Haidt, 2003). Figure 3 (link 7) shows that $B$, the recipient of moral benefits, feels gratitude and forms reciprocal intentions toward $\mathrm{A}$, the benefactor or moral motivator, eliciting 
a "virtuous circle" (Tangney et al., 2007a). The mechanism responsible is the norm of reciprocity (Zollo et al., 2017b), a universal principle of persuasion that obligates "individuals to repay in kind what they have received" (Cialdini, 2001, p.76). Gratitude and reciprocal altruism are based on social psychology and consumer behavior research stressing that "attitude alignment" (Davis and Rusbult, 2001) and mimicking (van Baaren et al., 2004) are highly persuasive (Tanner et al., 2008).

Cognitive empathy (link 8b) explains these reciprocal mechanisms. B takes A's emotional perspective (Haidt, 2003; Tangney et al., 2007a): hence, A's emotional processing influences B's moral awareness ${ }^{11}$. Thus, B's cognitive empathy causes B to understand/mentalize A's emotional processing (Shamay-Tsoory et al., 2009; Smith, 2006), activating B's moral awareness, moral judgment, moral intent, and moral behavior (Rest, 1986). Because A's emotional processing is the affective component of moral intuition (Evans, 2008; Greene et al., 2001), cognitive empathy allows A's moral intuition to directly activate B's moral reasoning. As a result, B takes A's moral intuitive perspective (Eisenberg et al., 2014; Tangney et al., 2007a). Consistently, symbolic interactionism terminology explains that B "structures" moral reasoning and moral behavior in accordance with A (Blumer, 1969; Mead, 1934). By taking the others' role, individuals can estimate the effect of symbolic configurations on communication recipients (Solomon, 1983, p.321). In other words, B's cognitive empathy allows B to be receptive (morally aware) and affectively persuaded by A's emotional needs and perception. B then "feels" and becomes morally aware of A's feelings (emotional processing) and acts prosocially toward A (Haidt, 2003). Indeed, mimicking leads to prosociality. "Being mimicked creates feelings of rapport, affiliation, and closeness toward the mimicker" (Tanner et al., 2008, p.755), which

\footnotetext{
${ }^{11}$ Link $8 \mathrm{~b}$ is consistent with the notion of emotional intelligence, "the subset of social intelligence that involves the ability to monitor one's own and others' feelings and emotions, to discriminate among them and to use this information to guide one's thinking and actions" (Salovey and Mayer, 1989, p.189) Hence, as shown in link 8b, A's emotional processing will be "rationalized" by B's moral awareness, leading to moral intent and ethical action (Chowdhury, 2017a).
} 
automatically and spontaneously fosters prosocial emotions, intuitive moral judgment, and positive reciprocal behavior (Zollo et al., 2017b). Consistent with the socially oriented approach, significant others' behaviors influence consumption behaviors (Cherrier, 2007; Cherrier and Murray, 2007; Shaw and Clarke, 1999). Because of the "chameleon effect" (Chartrand and Bargh, 1999), consumers spontaneously and unconsciously form moral intuition consistent with the behavior of others interacting in the same social setting (Kulesza et al., 2014). Therefore, we propose:

Proposition 5: A feedback loop of empathetic prosocial behavior occurs when consumers influence others in their group to choose ethical behavior; the others are grateful and reciprocate by acting prosocially, evoking additional ethical behavior in the social group.

Each social link works from consumer A toward consumer B and vice-versa (Haidt, 2001). As a result, B's moral intuition forms intuitive moral judgments; B's intuitive moral judgments influences moral reasoning; B's moral reasoning influences A's moral intuition through reasoned persuasion; similarly, B's intuitive moral judgment influences A's affect-laden intuition thanks to social persuasion. Finally, the "prosocial link" works from A toward B. Accordingly, the moral emotions component (elevation, gratitude, and affective/cognitive empathy) work from B toward A as well. Overall, the social intuitionist framework proposes that (1) emotions cause moral intuitive judgments to be affectively charged; (2) moral intuition forms intuitive moral judgments a priori and moral reasoning then rationalizes, re-evaluates, and justifies moral judgments post hoc; (3) moral emotions and intuition determine affective persuasion and social influence in ethical thinking and consumption; (4) moral intuition is enhanced and prosociality is increased when consumers perceive that they have ethically persuaded others. 


\section{Implications for ethical consumption research}

Our social intuitionist framework of ethical consumption has important implications for theory and practice and contributes to current integrated models of ethical decision making (Dedeke, 2015; Schwartz, 2016). That is, we apply the social intuitionist perspective (Haidt, 2001) to propose a descriptive integrated, holistic model of consumers' ethical decision making. The model considers System 1 comprising nonrational elements such as emotions and intuition, and System 2 comprising moral reasoning elements, including moral awareness, judgment, intent, and behavior. The traditional rationalist perspective cannot concretely depict ethical consumption (Shaw and Clarke, 1999; Vitell et al., 2003). Instead, the model blends features of important intuitionist and rationalist perspectives (Zollo et al., 2017a). Thus Systems 1 and 2 processes are joined with modern cognitive science (Evans, 2008; Kahneman, 2003) to fill gaps in explorations of antecedents of ethical decision making (Chowdhury, 2017a; Yacout and Vitell, 2018). Particularly focusing on ethical consumption, the model aligns with literature stressing the important role of emotions (Vitell et al., 2013) and intuition (Sekerka and Bagozzi, 2007; Zollo et al., 2018). In this way, the model illustrates the underlying interplay between rational and nonrational cognitive mechanisms in consumers' ethical thinking.

The model also considers the "social" component of Haidt's (2001) framework. Scholars have mainly focused on inner psychological mechanisms underlying ethical decision making (Woicheshyn, 2011) and have not appropriately considered that interpersonal social relationships, attitudes toward others, and social consensus are fundamental (Albert et al., 2015). Our model theorizes that subconscious and conscious psycho-sociological mechanisms underlie moral intuition and moral reasoning to generate affective persuasion and social influence (Argo et al., 2005; 
McFerran et al., 2009; Tanner et al., 2008). Further, we advance current ethical consumption literature predominantly built on a single theoretical domain (Islam, 2019; Shaw et al., 2016b) by taking an interdisciplinary perspective considering psychological theories in the social intuitionist model (Haidt, 2001) and microsociological theories in symbolic interactionism (Mead, 1934).

Integrated models of ethical decision making should help consumer ethics scholars better investigate nonrational elements such as emotions, intuition, and unconscious processes underlying conscious ethical behaviors and determining interpersonal persuasion and influence. Because ethical consumers are "socially embedded" and self-construct their identity through social relations (Connolly and Prothero, 2008) and ethical consumption is a "social experience" (Cherrier, 2007), we must understand how nonrational cognitive elements (1) elicit ethical decision making and behavior (Sekerka and Bagozzi, 2007; Vitell et al., 2013) and (2) persuade and influence other consumers' ethical behavior (Childers and Rao, 1992; Shaw and Clarke, 1999). Although the business ethics literature has largely neglected specific influences of interpersonally engaging moral emotions, our model recognizes their major contributions to ethical decision making. Scholars should rediscover the importance of moral emotions and thus explore the unconscious cognitive elements that shape ethical consumption.

\section{Implications for managers}

Practitioners can draw benefits from the social intuitionist framework of consumers' ethical decision making. First, marketing managers and practitioners can clearly identify where they might elicit nonrational cognitions that will persuade consumers to make ethical decisions. In particular, marketing advertisers should stress that ethical consumption can have positive effects "such as evoking positive memories and 
allowing enjoyable experiences" (Zollo et al., 2018, p.706). Emotive and intuitive responses lead to reflexive and quick moral judgments, so messages should evoke immediate positive perceptions that will foster moral reasoning. In particular, given the rising phenomenon of "ethical blindness" (Palazzo et al., 2012) in which consumers fail to recognize ethical dimensions of their decisions, managers should be aware that consumers may easily deviate from their instinctive and automatic ethical inclinations if they excessively rely on moral reasoning. Ethical blindness is usually associated with insensitivity to ethical dilemmas, as occurs in typical moral reasoning through re-evaluation and rationalization (Sonenshein, 2007). Thus ethical advertising and marketing communication should avoid being too focused on consequential, utilitarian, and preference-based logic and causing consumers to overly rationalize ethical dilemmas rather than using spontaneous moral orientations (Zollo et al., 2017a).

The model offers important macro-societal level insights by showing that unconscious emotions and moral intuition significantly impact moral awareness which then persuades other socially embedded consumers to act prosocially (Cherrier and Murray, 2007; Connolly and Prothero, 2008; Shaw et al., 2006). That is, managers should use the purchase/consumption environment to evoke ethical consumption (He et al., 2018), using the persuasion principles of reciprocity, liking, and social consensus for influencing ethical consumerism (Cialdini, 2001). For example, they might create empathetic social interactions and interdependent relationships (Kim and Johnson, 2013) by offering consumers opportunities to exchange personal information in a specific physical/online environment, perhaps fostering affective persuasion and social influence (Argo et al., 2005; Mcferran et al., 2009; Tanner et al., 2008), as described in the model. Another strategy could be to elicit moral emotions such as elevation, gratitude, and empathy (Haidt, 2001; Tangney et al., 2007a) through ethical celebrity 
endorsement (Miller and Laczniak, 2011). Advertisements about a celebrity's values of honesty, responsibility, fairness, respect, transparency, and citizenship (Miller and Laczniak, 2011, p.502) might be both rationally and nonrationally persuasive and begin a virtuous circle of ethical decision making and behavior. Advertisements might tell consumers about a product's environmental friendliness, a company's charitable activities, and a brand's corporate social responsibility, to encourage prosocial feelings, affective persuasion, and social influence (Kim and Johnson, 2013). To actively develop and foster empathy, marketers should focus on ethical branding by emphasizing their pro-social and environmental credentials (Chowdhury, 2017a). Similarly, advertisers can try to encourage ethical consumption through (1) awareness and empathy regarding consumer needs, (2) gratitude for patronage of eco-friendly products or services, (3) interest in consumer needs, expectations, and purchase experiences; and (4) respect and kindness for all stakeholders, especially consumers. Consistently, the social intuitionist framework suggests that managers should activate affective and cognitive empathy to enhance intuitive moral judgment (link 8a) and moral awareness (link 8b), respectively.

Overall, the proposed theoretical framework may benefit policymakers interested in fostering ethical consumption by revealing how they can persuade consumers to think and behave ethically.

\section{Conclusion}

Psychology and management scholars are increasingly challenging the traditional rationalist perspective that focuses on moral reasoning as the force behind ethical consumption. Instead, they are emphasizing unconscious elements such as emotions and moral intuition. Based on social intuitionist theory (Haidt, 2001) and symbolic interactionism (Mead, 1934), we propose the social intuitionist framework of 
consumers' ethical decision making (1) to provide an integrated and holistic framework to better understand how nonrational and rational cognitive elements interact in ethical considerations, and (2) to show how consumers may be affectively persuaded and socially influenced, creating prosocial dynamic loops.

Overall, we contribute to the ethical consumption literature by combining sociopsychological and microsociological perspectives to investigate affective persuasion and social influence among ethical consumers. Specifically, we are the first to theorize a conceptual model illustrating how consumers' moral emotions and moral intuition will directly influence other consumers' ethical decision making and behavior. The work is theoretically relevant for enhancing understandings regarding the cognitive antecedents and micro-mechanisms underlying ethical decision making (Albert et al., 2015; Yacout and Vitell, 2018) and showing how moral reasoning and behaviors have expansive influence (Kim and Johnson, 2013). Also, by identifying the cognitive mechanisms that foster affective persuasion and social influence in ethical decision making, we provide several practical implications for managerial strategies and policies focused on enhancing ethical consumption (Connolly and Prothero, 2008; Shaw et al., 2006; Vitell et al., 1991).

\section{Limitations and future research}

The paper has limitations mainly because the investigation is theoretical and the suggested propositions are not supported by empirical evidence. Future research could test the model in an experimental setting to empirically validate the assumptions that (1) moral intuition precedes moral reasoning (links 1 and 2 of the model), for example by testing whether emotions and intuition occur before awareness, judgment, and intent; (2) ethical decision making is influenced by other consumers' moral intuition and moral reasoning (links 3 and 4); (3) consumers are persuaded by ethical decision 
making and behavior of consumers they have primarily influenced (link 5); and (4) moral emotions such as elevation (link 6), gratitude (link 7), and empathy (link 8) significantly elicit affective persuasion and social influence.

Consumer researchers have empirically tested whether emotion, intuition, and persuasion impact consumers' decision making, preferences, and behavior. For example, an experimental setting was used to manipulate consumer dependency on their emotional system (Lee et al., 2009). Specifically, the authors compared consumer product preferences and trust in their emotions after they observed pictures and colored photos, which evoke higher emotional processing stimuli rather than words, symbols and black and white photos, which evoke lower emotional processing stimuli. The study indicated that consumers tend to rely on emotion and affective responses more than on reasoning to make consumption decisions. In another study (Tanner et al., 2008), consumers were shown to automatically mimic snack food preferences of strangers; in return, the strangers inadvertently displayed prosocial attitudes toward the mimickers by helping them achieve specific rewards (see also McFerran et al., 2009). In a test observing whether gratitude and empathy persuaded prosocial consumerism (Goenka and Van Osselaer, 2019), the authors used flyers/advertisements and emotion-recall writing tasks and found that "moral congruency of positive emotions can be employed to influence preferences and behaviors" (p.13). Those experimental settings might be applied to ethical consumption scenarios to empirically demonstrate the significant role of moral emotions, intuition, and persuasion on ethical consumerism. For example, researchers should test whether consumers will adopt more rapid, effortless, and automatic emotive/intuitive levels or slower, effortful, and deliberated rational levels when they observe visual stimuli, when they listen to verbal stimuli, or when they physically interact with stimuli. Further, it might be relevant to 
assess whether these assumptions work differently in individualistic and collective cultures, using the self-construal perspective (Kim and Johnson, 2013).

Future researchers should also theorize and test whether the theoretical propositions work differently among consumers who are (1) acquaintances or strangers, (2) ethical or non-ethical, (3) completely "disinterested" or highly connected, and (4) share mutual affection or dislike. Besides, future studies might better explore ethical consumption by taking different perspectives; using psychological theories such as social exchange theory or social identity theory in respect to social intuitionism or using sociological theories such as social action theory and structural functionalism in respect to symbolic interactionism. In addition, principles of social influence such as reciprocity, liking, and social consensus (Cialdini, 2001) might be better examined in relation to the model. Insights might be derived from a deeper analysis of the role played by moral emotions, either negatively or positively valenced (Haidt, 2003; Tangney et al., 2007a; b). For example, the "other-condemning" emotions of contempt, righteous anger, and disgust or the "self-conscious" emotions of shame, embarrassment, guilt, and moral pride (Haidt, 2003; Tangney et al., 2007a) might be powerful for preventing or condemning unethical behavior. Moreover, future scholars could investigate how the emotive-intuitionist components of the proposed framework influence traditional models and approaches. For example, the unconscious elements proposed in the social intuitionist model of ethical consumption might influence normative beliefs and subjective norms of the TPB (Ajzen, 1991). Similarly, scholars could assess whether moral emotions and intuition counter the attitude-behavior gap (Carrington et al., 2016; Caruana et al., 2016; Shaw et al., 2016a).

Although the literature has been mainly rooted in a rationalist perspective, the proposed emotive-intuitionist model might be useful both theoretically and practically 
for investigating the inner cognitive mechanisms explaining why consumers do not always act according to their ethical intentions.

\section{References}

Ajzen, I. (1991). The theory of planned behavior. Organizational Behavior and Human Decision Processes 50(2), 179-211.

Albert, L.S., Reynolds, S.J., \& Turan, B. (2015). Turning inward or focusing out? Navigating theories of interpersonal and ethical cognitions to understand ethical decision-making. Journal of Business Ethics 130(2), 467-484.

Argo, J.J., Dahl, D.W., \& Manchanda, R.V. (2005). The influence of a mere social presence in a retail context. Journal of Consumer Research 32(2), 207-212.

Belk, R.W. (1988). Possessions and the extended self. Journal of Consumer Research 15(2), 139-168.

Blumer, H. (1969). Symbolic Interactionism: Perspective and Method. Englewood Cliffs, Prentice-Hall, NJ.

Burke, L.A., \& Miller, M.K. (1999). Taking the mystery out of intuitive decision making. Academy of Management Executive 13(4), 91-99.

Carlson, D.S., Kacmar, K.M., \& Wadsworth, L.L. (2009). The impact of moral intensity dimensions on ethical decision-making: Assessing the relevance of orientation. Journal of Managerial Issues 21(4), 534-551.

Carrington, M.J., Zwick, D., \& Neville, B. (2016). The ideology of the ethical consumption gap. Marketing Theory 16(1), 21-38.

Caruana, R., Carrington, M.J., \& Chatzidakis, A. (2016). "Beyond the AttitudeBehaviour Gap: Novel Perspectives in Consumer Ethics": Introduction to the Thematic Symposium. Journal of Business Ethics 136(2), 215-218. 
Chartrand, T.L., \& Bargh, J.A. (1999). The chameleon effect: the perception-behavior link and social interaction. Journal of Personality and Social Psychology 76(6), 893.

Chatzidakis, A., Shaw, D., \& Allen, M. (2018). A psycho-social approach to consumer ethics. Journal of Consumer Culture. DOI: 10.1177/1469540518773815.

Cherrier, H. (2007). Ethical consumption practices: co-production of self-expression and social recognition. Journal of Consumer Behaviour: An International Research Review 6(5), 321-335.

Cherrier, H., \& Murray, J.B. (2007). Reflexive dispossession and the self: constructing a processual theory of identity. Consumption Markets \& Culture 10(1), 1-29.

Cherry, J., \& Caldwell, J. (2013). Searching for the origins of consumer ethics: bridging the gap between intuitive values and consumer ethical judgments. Marketing Management Journal 23(2), 117-133.

Chowdhury, R.M., \& Fernando, M. (2014). The relationships of empathy, moral identity and cynicism with consumers' ethical beliefs: The mediating role of moral disengagement. Journal of Business Ethics 124(4), 677-694.

Childers, T.L., \& Rao, A.R. (1992). The influence of familial and peer-based reference groups on consumer decisions. Journal of Consumer Research 19(2), 198-211.

Chowdhury, R.M. (2017a). Emotional intelligence and consumer ethics: The mediating role of personal moral philosophies. Journal of Business Ethics 142(3), $527-548$.

Chowdhury, R.M. (2017b). The Moral Foundations of Consumer Ethics. Journal of Business Ethics, 1-17. DOI: 10.1007/s10551-017-3676-2.

Chowdhury, R.M., \& Fernando, M. (2014). The relationships of empathy, moral identity and cynicism with consumers' ethical beliefs: The mediating role of moral disengagement. Journal of Business Ethics 124(4), 677-694. 
Cialdini, R.B. (2001). The science of persuasion. Scientific American 284(2), 76-81.

Cooley, C.H. (1902). Human Nature and the Social Order. Charles Scribner's, New York, NJ.

Connolly, J., \& Prothero, A. (2008). Green consumption: Life-politics, risk and contradictions. Journal of Consumer Culture 8(1), 117-145.

Dahl, D. (2013). Social influence and consumer behavior. Journal of Consumer Research 40(2), 3-5.

Dane, E., \& Pratt, M.G. (2007). Exploring intuition and its role in managerial decision making. Academy of Management Review 32(1), 33-54.

Davis, J.L., \& Rusbult, C.E. (2001). Attitude alignment in close relationships. Journal of Personality and Social Psychology 81(1), 65-84.

Dedeke, A. (2015). A cognitive-intuitionist model of moral judgment. Journal of Business Ethics 126(3), 437-457.

Eisenberg, N., Shea, C.L., Carlo, G., \& Knight, G.P. (2014). Empathy-related responding and cognition: A "chicken and the egg" dilemma. Handbook of Moral Behavior and Development 2, 63-88.

Evans, J.S.B. (2008). Dual-processing accounts of reasoning, judgment, and social cognition. Annual Review of Psychology 59, 255-278.

Ferrell, O., \& Gresham, L.G. (1985). A contingency framework for understanding ethical decision making in marketing. Journal of Marketing 49, 87-96.

Forbes (2017). Millennials driving brands to practice socially responsible marketing. Available at: https://www.forbes.com/sites/sarahlandrum/2017/03/17/millennialsdriving-brands-to-practice-socially-responsible-marketing/\#4e6e8a5a4990.

Gaudine, A., \& Thorne, L. (2001). Emotion and ethical decision-making in organizations. Journal of Business Ethics 31(2), 175-187. 
Goenka, S., \& van Osselaer, S.M. (2019). Charities Can Increase the Effectiveness of Donation Appeals by Using a Morally Congruent Positive Emotion. Journal of Consumer Research. DOI: 10.1093/jcr/ucz012.

Greene, J.D., Sommerville, R.B., Nystrom, L.E., Darley, J.M., \& Cohen, J.D. (2001). An fMRI investigation of emotional engagement in moral judgment. Science 293(5537), 2105-2108.

Haidt, J. (2000). The positive emotion of elevation. Prev. Treat. 3. Article 3. http://journals.apa.org/prevention/volume3/pre0030003c.html.

Haidt, J. (2001). The emotional dog and its rational tail: a social intuitionist approach to moral judgment. Psychological Review 108(4), 814-834.

Haidt, J. (2003). The moral emotions. In R. J. Davidson, K. R. Scherer, \& H. H. Goldsmith (Eds.), Handbook of affective sciences, (pp.852-870). Oxford University Press, Oxford.

Haidt, J. (2005). Invisible fences of the moral domain. Behavioral and Brain Sciences 28(4), 552-552.

Harrison, R., Newholm, T., \& Shaw, D. (2005). The ethical consumer. Sage, London, UK.

Hunt, S.D., \& Vitell, S. (1986). A general theory of marketing ethics. Journal of Macromarketing 6(1), 5-16.

Iacoboni, M. (2009). Imitation, empathy, and mirror neurons. Annual Review of Psychology 60, 653-670.

Islam, G. (2019). Psychology and Business Ethics: A Multi-level Research Agenda. Journal of Business Ethics, 1-13. DOI: 10.1007/s10551-019-04107-w.

Jones, T.M. (1991). Ethical decision making by individuals in organizations: An issuecontingent model. Academy of Management Review 16(2), 366-395. 
Kahneman, D. (2003). A perspective on judgment and choice: Mapping bounded rationality. American Psychologist 58(9), 697-720.

Kim, J.E., \& Johnson, K.K. (2013). The impact of moral emotions on cause-related marketing campaigns: A cross-cultural examination. Journal of Business Ethics 112(1), 79-90.

Kulesza, W., Szypowska, Z., Jarman, M.S., \& Dolinski, D. (2014). Attractive Chameleons Sell: The Mimicry-Attractiveness Link. Psychology \& Marketing $31(7), 549-561$.

Langer, E.J. (1978). Rethinking the role of thought in social interaction. New Directions in Attribution Research 2(1), 35-58.

Lee, L., Amir, O., \& Ariely, D. (2009). In search of homo economicus: Cognitive noise and the role of emotion in preference consistency. Journal of Consumer Research, 36(2), 173-187.

McFerran, B., Dahl, D.W., Fitzsimons, G.J., \& Morales, A.C. (2009). I'll have what she's having: Effects of social influence and body type on the food choices of others. Journal of Consumer Research 36(6), 915-929.

Mead, G.H. (1934). Mind, Self, and Society. The University of Chicago Press, Chicago, IL.

Miller, F.M., \& Laczniak, G.R. (2011). The ethics of celebrity-athlete endorsement: What happens when a star steps out of bounds? Journal of Advertising Research 51(3), 499-510.

Muncy, J.A., \& Vitell, S.J. (1992). Consumer ethics: An investigation of the ethical beliefs of the final consumer. Journal of Business Research 24(4), 297-311.

Nielsen (2015). The sustainability imperative: New insights on consumer expectations. Available at: https://www.nielsen.com/content/dam/nielsenglobal/dk/docs/globalsustainability-report-oct-2015.pdf. 
Palazzo, G., Krings, F., \& Hoffrage, U. (2012). Ethical blindness. Journal of Business Ethics 109(3), 323-338.

Rest, J.R. (1986). Moral development: Advances in research and theory. Praeger Publishers, New York.

Salazar, H.A., Oerlemans, L., \& van Stroe-Biezen, S. (2013). Social influence on sustainable consumption: evidence from a behavioural experiment. International Journal of Consumer Studies 37(2), 172-180.

Salovey, P., \& Mayer, J.D. (1989). Emotional intelligence. Imagination, Cognition and Personality 9(3), 185-211.

Schwartz, M.S. (2016). Ethical decision-making theory: An integrated approach. Journal of Business Ethics 139(4), 755-776.

Sekerka, L.E., \& Bagozzi, R.P. (2007). Moral courage in the workplace: Moving to and from the desire and decision to act. Business Ethics: A European Review $16(2), 132-149$.

Shamay-Tsoory, S.G., Aharon-Peretz, J., \& Perry, D. (2009). Two systems for empathy: a double dissociation between emotional and cognitive empathy in inferior frontal gyrus versus ventromedial prefrontal lesions. Brain, 132(3), 617627.

Shaw, D., Carrington, M., \& Chatzidakis, A. (2016b). Ethics and morality in consumption: interdisciplinary perspectives (Vol. 8). Routledge, New York, NJ.

Shaw, D., \& Clarke, I. (1999). Belief formation in ethical consumer groups: an exploratory study. Marketing Intelligence \& Planning 17(2), 109-120.

Shaw, D., McMaster, R., \& Newholm, T. (2016a). Care and commitment in ethical consumption: An exploration of the 'attitude-behaviour gap'. Journal of Business Ethics 136(2), 251-265. 
Shaw, D., Newholm, T., \& Dickinson, R. (2006). Consumption as voting: an exploration of consumer empowerment. European Journal of Marketing 40(9/10), 1049-1067.

Smith, A. (2006). Cognitive empathy and emotional empathy in human behavior and evolution. The Psychological Record, 56(1), 3-21.

Solomon, M.R. (1983). The role of products as social stimuli: A symbolic interactionism perspective. Journal of Consumer Research 10(3), 319-329.

Sonenshein, S. (2007). The role of construction, intuition, and justification in responding to ethical issues at work: The sensemaking-intuition model. Academy of Management Review 32(4), 1022-1040.

Tangney, J.P., Stuewig, J., \& Mashek, D.J. (2007a). Moral emotions and moral behavior. Annual Review of Psychology 58, 345-372.

Tangney, J.P., Stuewig, J., \& Mashek, D.J. (2007b). What's moral about the selfconscious emotions. In Tracey, J., Robins, R.W., Tangney, J.P. (Eds.) The selfconscious emotions: Theory and research, 21-37.

Tanner, R.J., Ferraro, R., Chartrand, T.L., Bettman, J.R., \& Baaren, R.V. (2008). Of chameleons and consumption: The impact of mimicry on choice and preferences. Journal of Consumer Research 34(6), 754-766.

Turner, J.C. (1982). Towards a cognitive redefinition of the social group. In H. Tajfel (Ed.), Social identity and intergroup relations (pp.15-40). Cambridge University Press, Cambridge, UK.

van Baaren, R.B., Holland, R.W., Kawakami, K., \& van Knippenberg, A. (2004). Mimicry and Prosocial Behavior, Psychological Science 15(1), 71-74.

Vitell, S.J. (2003). Consumer ethics research: Review, synthesis and suggestions for the future. Journal of Business Ethics 43(1-2), 33-47. 
Vitell, S.J., King, R.A., \& Singh, J.J. (2013). A special emphasis and look at the emotional side of ethical decision-making. AMS Review 3(2), 74-85.

Vitell, S.J., Lumpkin, J.R., \& Rawwas, M.Y. (1991). Consumer ethics: An investigation of the ethical beliefs of elderly consumers. Journal of Business Ethics 10(5), 365-375.

Yacout, O.M., \& Vitell, S. (2018). Ethical consumer decision-making: The role of need for cognition and affective responses. Business Ethics: A European Review 27(2), 178-194.

Zajonc, R.B. (1980). Feeling and thinking: Preferences need no inferences. American Psychologist 35(2), 151-175.

Zollo, L., Faldetta, G., Pellegrini, M.M., \& Ciappei, C. (2017b). Reciprocity and giftgiving logic in NPOs. Journal of Managerial Psychology 32(7), 513-526.

Zollo, L., Pellegrini, M.M., \& Ciappei, C. (2017a). What sparks ethical decision making? The interplay between moral intuition and moral reasoning: lessons from the scholastic doctrine. Journal of Business Ethics 145(4), 681-700.

Zollo, L., Yoon, S., Rialti, R., \& Ciappei, C. (2018). Ethical consumption and consumers' decision making: the role of moral intuition. Management Decision 56(3), 692-710. 